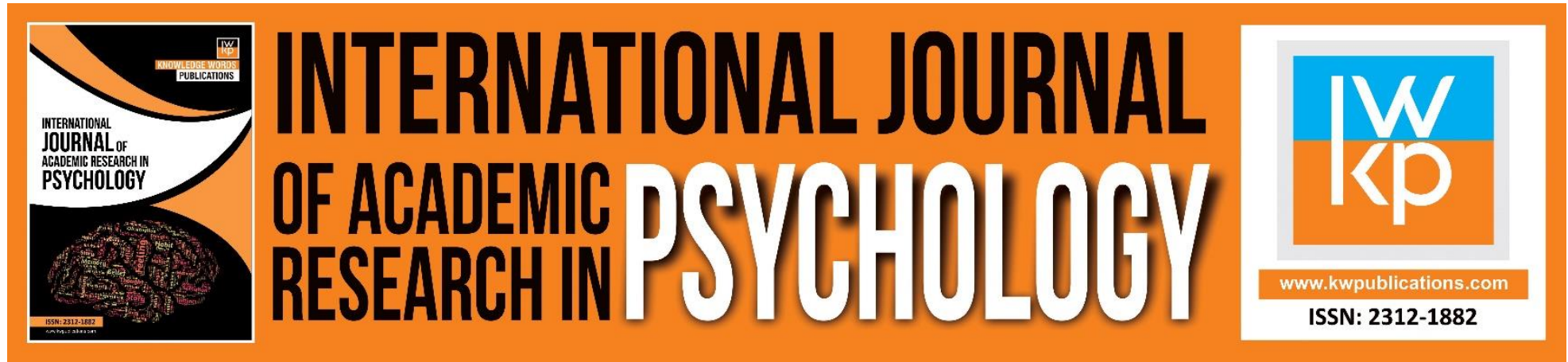

\title{
A Study of Exploring the Indicators of Prosocial Behavior among Adolescents of Bangladesh
}

Alpona Shirin

To Link this Article: http://dx.doi.org/10.46886/IJARP/v6-i1/6394

DOI:10.46886/IJARP/v6-i1/6394

Received: 08 April 2019, Revised: 23 May 2019, Accepted: 16 June 2019

Published Online: 29 July 2019

In-Text Citation: (Shirin, 2019)

To Cite this Article: Shirin, A. (2019). A Study of Exploring the Indicators of Prosocial Behavior among Adolescents of Bangladesh. International Journal of Academic Research in Psychology, 6(1), 30-40.

Copyright: (C) 2019 The Author(s)

Published by Knowledge Words Publications (www.kwpublications.com)

This article is published under the Creative Commons Attribution (CC BY 4.0) license. Anyone may reproduce, distribute, translate and create derivative works of this article (for both commercial and non-commercial purposes), subject to full attribution to the original publication and authors. The full terms of this license may be seen

at: http://creativecommons.org/licences/by/4.0/legalcode

Vol. 6, No. 1, 2019, Pg. 30 - 40

https://kwpublications.com/journals/journaldetail/IJARP

JOURNAL HOMEPAGE

Full Terms \& Conditions of access and use can be found at https://kwpublications.com/pages/detail/publication-ethics 


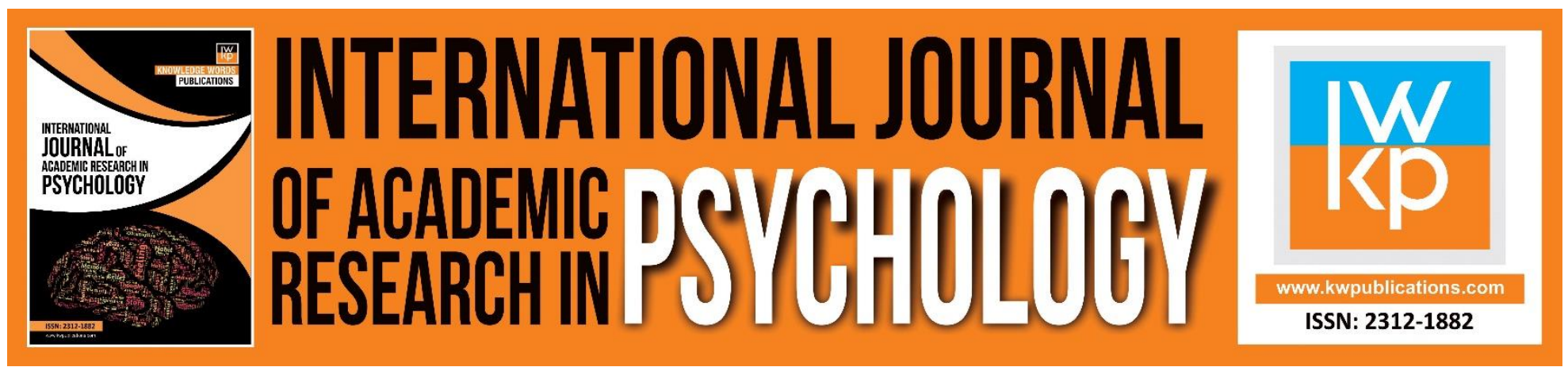

\title{
A Study of Exploring the Indicators of Prosocial Behavior among Adolescents of Bangladesh
}

\author{
Alpona Shirin \\ University of Dhaka, Bangladesh \\ Email: alpona.shirin@gmail.com
}

\section{Abstract}

The present study aimed to explore the indicators of prosocial behaviors among adolescents of Dhaka city. A total 60 participants of age 13 to 15 from three different secondary school (Grade IX) of Dhaka city were engaged in data collection through Focus Group Discussions (FGDs). Ten students from each section of the three different schools (one boy's, one girl's and one co-education) were chosen for FGDs to explore the factors that indicate prosocial behavior. Data analysis followed thematic analysis. The findings showed that students perceived prosocial behavior as social behavior, tendency of sharing, peer acceptance, maintaining social rules, personality and so on as indicators of prosocial behavior.

Keywords: Prosocial Behavior, Behavior Indicators, Adolescents.

\section{Introduction}

Social scientists used the word 'prosocial' first as an antonym of antisocial (Kruglanski \& Stroebe, 2012). People also often asked social psychologists about the reason 'why and why not people act 'prosocially' (Reynolds, Miller, \& Weiner, 2003; Khalid, Islam, \& Ahmed, 2019). As a definition prosocial behavior "is the label of a broad category of deeds which are defined by society as generally helpful to other people" (Piliavin et al., 1981, p. 4). About the indicators of prosocial behavior there is assorted variety insight into empirical research studies. The components of social behavior have some natural properties like as "peer acceptance", "social competence", "friendship" and so on (Spasenovic, 2004). Basically, social behavior can be showed positive as well as negative. Positive social behavior which includes prosocial approach provides characteristics to build up interrelationships with other humans. In some studies, prosocial behavior indicates behavior like helping others, cooperation, sharing, comforting others, provide encouragement and support and less commonly psychological support (Jackson \& Tisak, 2001; Spasenovic, 2004; Reynolds, Miller, \& Weiner, 2003; Alzgool, 2019). Penner and Finkelstein (1998) suggested prosocial behavior as

"an enduring tendency to think about the welfare and rights of other people, to feel concern and empathy for them, and to act in a way that benefits them"

A child can help their peers because of creating a friendly relation with peers or it expects recognition from teachers. Child can do that because of dealing with others welfare or a feeling of 
INTERNATIONAL JOURNAL OF ACADEMIC RESEARCH IN PSYCHOLOGY

Vol. 6, No. 1, 2019, E-ISSN: 2312-1882 @ 2019 KWP

empathy (Spasenovic, 2004). In school context helping others are in the norms of 'Sharing', 'Cooperating', 'Providing help', 'Solving personal problem' or 'accomplishing a goal' (Spasenovic, 2004). 'Sharing' refers to giving or loaning their stuff (snacks, sweet and school supplies). 'Cooperation' refers to cooperate in learning, tackling issues, indicates willingness and capacity to work with others, frequently in common interests. Providing help and comfort implies willingness to meet the emotional need of others (brighten up somebody who is tragic, to praise, to cheer) (Spasenovic, 2004; Umrani, Ahmed \& Memon, 2015). Moreover, students build up shared relations in various social situations. The larger parts of these communications are accomplished at school.

An effective teaching-learning environment includes learner friendly and participatory environment in the classroom (Könings, Seidel \& Merriënboer, 2014). The students' participations are not remarkable for some unsighted complexity or indirect influence (Teaching Quality Improvement-II, 2015; Mustapha, Rahman \& Yunus, 2010). A total of 38.3\% students in secondary level of Bangladesh dropped out in 2016, this nonparticipative approach of students can be a reason of this. (BANBEIS, 2017). In Bangladeshi school context, teachers, parents as well as students crave for only good academic grades. (Kabir,2014) A common scenario of every secondary classroom of Bangladesh is that some students always response first in classroom in terms of participations. Moreover, children who have the initiative to be social in the classroom are also very popular to their teachers. In order to build and keep positive social relations among peers, behavioral, cognitive and affective skills are necessary for children (Salisch, 2001). However, if the students engage in different social activities like cooperative skills the cooperation between them will increase. The cooperation skill helps students engaging in cooperative learning rather individualistic learning (Johnson \& Johnson, 2004). And such behavioral practice from childhood may help to develop future citizen for a better cooperative society which is aim of 21st century development agenda. A series of studies have been conducted in other contexts to understand prosocial behavior and indicators factors or influencing prosocial behavior (Penner et al., 2005, Graziano et al., 2010, Reynolds, Miller, \& Weiner, 2003) However, in Bangladesh there is very little literature available regarding the indicators of prosocial behavior. In addition, there is no national level data to identify prosocial behavior among students. As being a member of a group, building up friendly relation, conflict resolution, communication skills, controlling behavior skills are the most important skills taught from the very beginning of the school, students belong the chance to express different types of prosocial behaviors like cooperation in common games or work, assisting in learning, solving problems, helping others in need, sharing school items used in the game, taking action for protecting peers and provide encouragement (Spasenovic, 2004). Though there are studies in problem behavior in the context of Bangladesh (Hossain, 2013), prosocial behavior remains unnoticed. If prosocial characteristics can be identified and provide a guideline to the students, teachers and their parents in Bangladeshi context, Student would engage more to a successful education program by participating in classroom which depicts a society of inclusiveness. Moreover, more participation of the students in the classroom for having prosocial behavior can also decrease dropout rate As in formal education system of Bangladesh there are very few opportunities to identify students prosocial behavior, exploring the indicators of prosocial behavior among adolescents was worth.

- The objective of the study was to understand prosocial behavior and exploring the indicators of prosocial behavior among adolescents. To achieve the purpose of this study, the following question guided my research-How do adolescents perceive prosocial behavior? 
INTERNATIONAL JOURNAL OF ACADEMIC RESEARCH IN PSYCHOLOGY

Vol. 6, No. 1, 2019, E-ISSN: 2312-1882 @ 2019 KWP

Research recommends that children's relative capacity to delay satisfaction is a significant indicator of social adjustment in adolescents (Mischel, Shoda and Peake, 1988). People get feedback from the surroundings regarding their goals, and they utilize that feedback to observe disparities between their actual selves and their idealized selves. They at that point try to change their characteristics to limit the apparent disparities (Higgins, 1987). According to McAdams theory of narrative identity (2001) generativity results from complex interconnections and inner forces. Motivation through intimacy and love is a concern for warm interpersonal encounters for their own sake. Moreover, intimacy motive has been shown to relate to positive outcomes (McAdams, 2013). However, regarding prosocial characteristics these affiliation needs in adolescents and different kinds of fulfillment of these motives is worth exploring. Understanding prosocial characteristics is important because if the indicators of the characteristics can be identified and can provide a guideline to the students in Bangladeshi context, Student would engage more to a successful education program by participating in classroom and also to a society of inclusiveness.

This study conducted within adolescents of age 13-15 from secondary school students (Grade IX) of Dhaka city. Though there are different literatures about indicators, predictors and factors of prosocial behavior (Reynolds, Miller, \& Weiner, 2003; Eisenberg, 2006; Dan, 2000; McMahon, Wernsman, \& Parnes, 2006; Flynn et al., 2015) the present study only looked for how students perceive prosocial behavior and about the indicators of prosocial behavior in the context of Bangladesh.

\section{Methodology}

The nature of the study was qualitative. Data was collected through Focus Group discussions (FGDs) from 60 students of secondary level especially students of Grade IX of Dhaka city. FGDs were conducted on three different schools including one boys' school, one girls' school and one coeducation school. Almost each Grade IX has two sections; one for science and one for humanities and commerce in Dhaka city. A total of 60 students were selected as participants of collecting data through FGDs. As the numbers of female students are not remarkable in most of schools, the participants indicate 35 males and 25 females for FGDs. Six FGDs were conducted including 10 participants in each FGD on three different schools. A non-probability purposive sampling technique was used for selecting schools and grades and participants for the reason of time constraints. The reason behind choosing three different types of school was to explore the indicators of prosocial behavior among different peers' settings like within boys, within girls and within a mix group.

The tool of FGDs was pilot tested within a small group of four students of grade IX. For conducting FGDs, based on the research question, several themes were developed to facilitate the discussion. In each FGDs, the themes remained same for the participants and the answers were taken by note-taking. Then after completing all FGDs some information as well as themes got common and based on thematic analysis researcher got thematic categories. The theme categories were extracted by content analysis of the text of FGDs. Basically, the content analysis was based on conceptual analysis of the concept 'Prosocial Behavior'. Researcher allowed flexibility to add categories through the frequency of a concept. The texts coded as the same when they appeared in different forms. Thus, the researcher drew seven generalized themes. Some uncommon answers were also coded as an indicator. Class teachers helped the researcher to select the students for conducting FGDs based on their observed behavior and academic achievements. Students were asked about the view and belief of social behavior. Each participant of FGDs has given enough time to express thoughts, beliefs, 
INTERNATIONAL JOURNAL OF ACADEMIC RESEARCH IN PSYCHOLOGY

Vol. 6, No. 1, 2019, E-ISSN: 2312-1882 @ 2019 KWP

attitude and reactions about prosocial behavior. The free and open discussions of each participant lasting for at least 15 minutes helped the researcher to generate new ideas about the indicators of prosocial behavior.

\section{Findings and Discussions}

The focus group discussion (FGD) generated the data about understanding of prosocial behavior. The findings exhibit students understanding about prosocial behaviour in multiple ways. Surprisingly, students explored prosocial characteristics in various ways among their peers. It indicates multiple indicators including social behaviour, tendency of sharing, social norms, acceptance, prominence and so on. In addition, researcher hypothesized about some differences in indicators from different peer settings and different schools but somehow regarding indictors of prosocial behaviour there didn't show any remarkable differences. The FGD produced seven themes as indicators of prosocial behavior in relation to students' understanding of prosocial behavior. Each of the themes is described below.

\section{Social Behavior}

Participants frequently stated that students who seem social peers have sociable behavior. Participants identified prosocial students as who can easily associate themselves with everyone. One student commented that, 'Social peers can associate with everyone easily.' Moreover, social peers always conduct anyone with a smiling face. They show polite behavior and have a positive attitude. Social peers can be friendly and behave well with all types of students without any discrimination. Another student mentioned that, 'For being social peer a social approach is a must. Social peers always make an approach first for making friends. 'On the contrary, about the matter of unsociable peer, participants said that unsociable peers often hide themselves. They do not response to a friendly approach and ignore peer interaction. Most of the participants said that unsociable peers cannot associate with anyone.

In some literatures of other contexts friends are supposed to be vital socializers of prosocial act also (Barry and Wentzel, 2006). "People will help others more when in a good mood for several reasons, including doing well on exam, receiving gifts, happy thinking, and tuning to pleasant music" (North, Tarrant\& Hargreaves, 2004). Good mood and attitude help people to interpret events in a sympathetic way which helps to act prosocially. Positive approaches also raise self-attention which helps one to act according to beliefs and values and it includes prosociality (Reynolds, Miller, \& Weiner, 2003). As in adolescent period, self-regulation turns out to be linked to the manner through which children monitor their own behavior regarding personal goals and ideals (Carver \& Scheier, 1982), social behavior can pave the way for positive contribution among the adolescents of Bangladesh.

\section{Tendency of Sharing}

Participants mostly said that social peers have sharing behavior with everyone. Participants also classified sharing in terms of social behavior. Participants mentioned that social peers share their thoughts, belongings and feelings and social peers provide help and receive help from others. As to unsociable peers, participants said that generally they do not share anything with anyone. One commented, 'Unsociable peers are so introvert. They even do not help others even if others need.'

Literature also suggested that students who have prosocial behavior have the uttermost tendency of sharing things. If anyone shares his belongings as well as feelings to anyone easily, they 
INTERNATIONAL JOURNAL OF ACADEMIC RESEARCH IN PSYCHOLOGY

Vol. 6, No. 1, 2019, E-ISSN: 2312-1882 @ 2019 KWP

became popular friends (Berk, 2006). Therefore, in Bangladeshi context being prosocial can be considered for adolescent students because tendency of sharing aka being friends can mitigate bullying or harassment incidents (Daily Star, 2019).

\section{Maintaining Social Rules}

Participants said that social peers usually follow all the social norms and those are kind of unwritten social rules. They respect the social norms like 'be clean and keep clean', 'be punctual', 'be industrious', 'Don't quarrel', maintain the norms and rules and encourage others to maintain the rules. But unsociable peers do not care about the social norms. A participant think unsociable children are arrogant. They avoid teachers and honorable persons and also disobey the norms of society. Peers who are unsociable usually do the opposite things what social peers do. One participant said, 'Unsociable peers normally get involved with wrongful act and affiliated with degenerated culture.' Participants commented that who maintain all the social norms fairly are having the prosocial characteristics Most of the participants said that unsociable children like to be undisciplined. They misbehave with peers as well as teachers. Moreover, a few participants said, 'Unsociable child misbehave with others, get involved with quarreling, fighting, different types of crimes even if get touched with drugs.'

Research findings also showed that social norms are another important indicator of prosocial behaviour (Reynolds, Miller, \& Weiner, 2003). In a society some unwritten rules are provided about the expected idea for behaving in a particular social group which is called social norms. It can vary from group to group. Naturally people learn that acting prosocially can bring rewards and also learn about the norms for the prosocial behavior which should be performed by one in different situations (Reynolds, Miller, \& Weiner,2003). These norms and roles provide the characteristics that one should help individuals in need to maintain a strategic distance from social or self-regulated approvals (Reynolds, Miller \& Weiner, 2003). If the adolescents of Bangladesh can be encouraged in maintaining social norms and rules for being prosocial, the country can expect an inclusive and peaceful society.

\section{Peer Acceptance}

Participants identified prosocial as peer acceptance. Social peers conduct with other students valuing their behavior and feelings and respecting their opinions. Social peers even help some unknown person to get access with. They can cope up and can go in a row with all types of students without hurting anyone. Some participants also said that social students also communicate with teachers, in the classroom they usually response first when teachers ask anything. They communicate with teachers as well as peers very well. Contrarily, unsociable peers avoid teachers and make disturbance in the classroom. Moreover, unsociable peers have tendencies to do harmful act and avoid socialism. One participant classified the socialness of unsociable students. He said,

'Unsocial peers are of two mottos, one who ignore any friendly approach and another who feel shy to be open. They are self-centered and not interested in socialism and generally they cope not up with us and don't value or respect other opinions.'

However, the reason of being unsociable of peers can be either ignoring or feeling shy to be open. However, unsociable peers are egocentric and not participate in socialization. Prosocial students normally offer acceptance by their behaviour to their peers. Participants commented that prosocial students can easily cope up with peers in all types of situations, they generally respect other opinions, help others voluntarily and do not harm people. 
INTERNATIONAL JOURNAL OF ACADEMIC RESEARCH IN PSYCHOLOGY

Vol. 6, No. 1, 2019, E-ISSN: 2312-1882 @ 2019 KWP

Social psychologists also suggested that people act prosocially to them who encourage them and do not harm those people (Gouldner, 1960). Moreover, in the degree to which children act prosocially and motivate to behave prosocially, children can be alike with their friends (Wentzel, Barry \& Caldwell, 2004).

\section{Personality}

Some participants think that social students are talented students of the class. They are extrovert and open minded. Social peers motivate others for doing good work and voluntary work for society. 'Sociable peers are empathetic. They easily can share their feelings and secrets to us. Thus, we also can share our thoughts and secrets to them', one participant said. Unsociable peers here look introvert and self-centered participants think. Peers who are unsociable feel superior anyhow. One mentioned that 'Unsociable children are arrogant. They usually tell lies deliberately and can do harm to peers and only give priorities to own opinion.'

Participants also commented prosocial personality as extrovert, open minded, empathetic, and voluntarily active (who help others voluntarily, cooperate with teachers and peers spontaneously, seems prosocial to me).

Researchers had been debating for a long time about human prosocial personality. Then according to Eisenberg (1999), researcher agreed about the existence of prosocial personality. The individual differences in prosocial dispositions become stable into adolescence and adulthood (Eisenberg et al., 1999). Moreover, Prosocialization may vary with individuals linking to empathy, sociability, agreeableness, low shyness, extroversion (Penner et al., 2005).

In addition, literature also suggests effect of positive mood, similarity and kinship and any situation can be the reason of acting prosocially (Reynolds, Miller, \& Weiner, 2003). However, in the context of Bangladesh the study did not find any specific factors of positive mood, similarity and situation. Possible reason might be that the participants of Grade IX still didn't face any helping situation, or they did not find any effect of mood and similarities to act prosocially. Moreover, they may also forget to mention the situation or effects, as it indicates the basics of prosocial act.

\section{Communication Skill}

Some participants perceived social students as expert in communicating. One participant commented, 'Social peers have the tendency to always response first in the class, so they are popular to peers as well as teachers. 'Social peers have good communication with teachers and teachers also take care of them. However, social peers maintain good relationship with teachers and their peers as well.

Literature showed that a child can help their peers because of creating a friendly relation with peers or it expects recognition from teachers. Child can do that because of dealing with others welfare or a feeling of empathy (Spasenovic, 2004). Moreover, School culture helps adolescents to acquire goal completeness in prosocial involvement (Lam, 2012). Therefore, in Bangladeshi perspectives, adolescents can contribute to an amiable environment by perceiving prosocial characteristics.

\section{Parenting Style}

Participants commented that sometimes peers who approach socially seems to be an innate quality of them which they received from their parents. Few participants stated that prosocial characteristics are associated with family style. One commented, 'Peers who seems very social to me, 
INTERNATIONAL JOURNAL OF ACADEMIC RESEARCH IN PSYCHOLOGY

Vol. 6, No. 1, 2019, E-ISSN: 2312-1882 @ 2019 KWP

their parents are also very sociable. I think social behavior comes from home and parents play very important role to flourish it.'

Research findings also suggested that Self-esteem, Peer influence, Parental involvement is significantly related and helpful to prosocial behavior (Ogunboyed \& Agokei, 2016). Moreover, Parents and teachers also help human to be prosocial as they are genetically predisposed (Lam, 2012). However, Studies found that parenting style particularly authoritative parenting style promote prosocial behavior in adolescents (Emagnaw \& Hong 2018). In the context of Bangladesh, parents may not be interested in socializing their children rather focus on achieve good results (bdnews, 2018). In that case, indicators of prosocial behavior can reflect the effectiveness of prosociality among adolescents.

\section{Limitations}

The study has some limitations on selecting samples, age limit and time constraints. As the sample of the study was of only 13-15 among adolescents where in Bangladesh the range of adolescents is $10-19$, the findings cannot be generalized for the whole population. . Though for the sample government, nongovernment and semi government schools were selected, the schools were from only Dhaka city. So there remains a chance for getting partial situation in the findings. The samples were also selected from only Grade IX where others grade of adolescents were not considered. Researcher selected one boys' school, one girls' school and one co-education school for sampling. But the numbers of male were more than double than females, as the number of female students is smaller in co-education school.

\section{Importance of Diverse Samples}

Series of studies indicated children who has shown positive characteristics such as empathy, agreeableness and peer acceptance have higher prosocial behavior (Penner et al., 2005, Graziano et al., 2010, Crick, 1996; Layous et al., 2012). However, literatures assist the researcher to guess some of indicators of prosocial behavior. The samples of the literatures are of diverse geographic like Italy, USA, Nigeria and China. All the samples of the literature also provided diversified the factors and indicators of prosocial behavior. The researcher then felt curious to explore the indicators in completely a different geographical area, Bangladesh. As the sample of the study was of only 13-15 among adolescents where in Bangladesh the range of adolescents is 10-19, the findings cannot be generalized for the whole population.

\section{Contribution to Social Psychology}

Society demands for more collaboration and cooperation among the people of the community. Therefore, it was important to explore how people can be more engaged to interpersonal relationships. According to Dovidio (2006) people can act prosocially by the influence of biological, situational, psychological, social and environmental factors. The findings of the study suggested the indicators that one can easily marked the prosocial act. In 'need to belong' theory Baumeister (2003) stated that feeling of rejection can cause harm to the society, thus people act prosocially to be engaged more with the society. However, the findings of the study suggest the indicators to feel included in the society. As the students of adolescents' age can't be engaged with prosocial characteristics, they may engage with some harmful acts and act irresponsibly to the society, indicators of prosocial behavior are a must to nourish the value of being prosocial. 
INTERNATIONAL JOURNAL OF ACADEMIC RESEARCH IN PSYCHOLOGY

Vol. 6, No. 1, 2019, E-ISSN: 2312-1882 @ 2019 KWP

\section{Conclusion}

The study suggests some indicators of prosocial behavior of adolescents of secondary school level of Bangladesh. For effective learning and a better cooperative society behavioral practice like promoting prosocial behavior is important. For promoting prosocial behavior identifying the indicators is a must. The major findings of the study are the indicators by which one can easily find prosocial characteristics out of the one. Indicators like social behavior, tendency of sharing and peer acceptance can be easily identified in classroom environment. Moreover, maintaining social rules and communication skills are the indicators which also seems easily visible to teachers, parents as well as peers. Therefore, findings of this study suggest some indicators that may help peers, parents as well as teachers to understand and determine prosocial behaviors. Furthermore, understanding of such indicators may help teacher and parents to support the students to practice and promote prosocial behaviors.

As adolescents is the age of engaging with harmful acts, students' parents, educators and surroundings should aware of promoting prosocial behavior and cooperative learning for preventing students, engaging with harmful acts. The findings of the study can assist to promote prosocial behavior through adolescents of the society. This study focused on the indicators of prosocial behaviors among adolescents of Bangladesh. As in Bangladesh the dropout rate is too much high and normally teachers are blamed for this high dropout rate, students may consider the issue for engaging in prosocial behavior. Thus, for being prosocial of the students, dropout rate can also be reduced. Educators may also motivate students for engaging in prosocial behaviors. This research is helpful to identify the indicators that may influence prosocial behaviors. Therefore, the findings may help to create supportive teacher-student relationship, home environment which helps children to be prosocial. As in the context of Bangladesh there are very few researches indicates indicators of prosocial behavior, the findings also provide useful information that contributed to theoretical knowledge on this perspective. In addition, by understanding prosocial behavior, students, teachers and parents can realize the effectiveness of the prosocial behavior in academic and social life. A school as well as classroom environment is substantial for optimizing prosocial behavior. As school context is undeniable for behavioral adjustment, there should be a national guideline for schools and teachers to promote prosocial behavior. Since parents may not interested to socialize their children rather focus on achieve good results in Bangladesh, a guideline of prosocial behavior known to children parents and students would also impact as important as achieving good academic achievement. Further study can be conducted for identifying the factors of prosocial behavior on a broader sample and a longitudinal study can also be conducted for determinants of prosocial behavior. Moreover, strategies to support social behavior should be included in teachers training and also in curriculum. The implications of this study unfold better understanding of the students' prosocial behaviour.

\section{References}

BANBEIS. (2017). Retrieved from http://www.thedailystar.net/country/38-percent-secondarystudents-drop-out-2016-bangladesh-education-banbeis-report-1408615.

Barry, C. M., \& Wentzel, K. R. (2006). Friend influence on prosocial behavior: The role of motivational factors and friendship characteristics. Developmental Psychology, 42(1), 153163.http://dx.doi.org/10.1037/0012-1649.42.1.153.

Berk, L. E. (2002). Child Development ( $9^{\text {th }}$ ed). 
INTERNATIONAL JOURNAL OF ACADEMIC RESEARCH IN PSYCHOLOGY

Vol. 6, No. 1, 2019, E-ISSN: 2312-1882 @ 2019 KWP

Caprara, G. V., Alessandri, G., Di Giunta, L., Panerai, L., \& Eisenberg, N. (2010). The Contribution of Agreeableness and Self-efficacy Beliefs to Prosociality. National Center for Biotechnology Information (NCBI),24(1), 36-55.doi: 10.1002/per.739.

Carver, C. S., \& Scheier, M. F. (1982). Control theory: A useful conceptual framework for personalitysocial, clinical, and health psychology. Psychological Bulletin, 92, 111-135.

Dan, L. (2000). A Study of Factors Influencing the Prosocial Behavior of Children. PSYCHOLOGICAL SCIENCE-SHANGHAI-, 23(3; ISSU 125), 285-288.

Eisenberg, N., Guthire, I. K., Murphy, B. C., Shepard, S. A., \& Cumberland, A. (1999). Consistency and Development of P rosocial Dispositions: A Longitudinal Study, Child Development, 70(6), 1360-1372.

Emagnaw, A. B., \& Hong, J. (2018). Relationship among Parenting Styles, Prosocial Behavior and School Performance of Students Who are Attending to Grade Seven and Eight State Schools. Journal of Sociology and Anthropology, 2(2), 44-50. DOI: 10.12691/jsa-2-2-1

Flynn, E., Ehrenreich, S. E., Beron, K. J., \& Underwood, M. K. (2015). Prosocial behavior: Long-term trajectories and psychosocial outcomes. Social Development, 24(3), 462-482.

Gouldner, A. W. (1960). The Norm of Reciprocity: A Preliminary Statement. American Sociological Review, 25(2), 161-178. DOI: 10.2307/2092623

Higgins, E. T. (1987). Self-discrepancy: a theory relating self and affect. Psychological review, 94(3), 319.

Hossain, S. (2013). A study of determining the relationship between academic achievement and problem behavior of urban secondary school students in Bangladesh. The International Journal of Social Science, 8(1), 001-010.

Jackson, M., \& Tisak, M. S. (2001). Is prosocial behaviour a good thing? Developmental changes in children's evaluations of helping, sharing, cooperating, and comforting. British journal of developmental psychology,19(3), 349-367, https://doi.org/10.1348/026151001166146

Johnson, D. W., \& Johnson, R. T. (2009). Introduction to cooperative learning. An Overview of Cooperative Learning. Retrieved, 13, 2014.

Kruglanski, A. W., \& Stroebe, W. (Eds.). (2012). Handbook of the history of social psychology. Psychology Press.

Könings, K. D., Seidel, T., \& Van Merriënboer, J. J. (2014). Participatory design of learning environments: integrating perspectives of students, teachers, and designers. Instructional Science, 42(1), 1-9.

Lam, C. M. (2012), Prosocial Involvement as a Positive Youth Development Construct: A Conceptual Review, The Scientific world journal, DOI: 10.1100/2012/769158

McAdams, D. P. (2001). The psychology of life stories. Review of general psychology, 5(2), 100-122.

McAdams, D. P., \& Cox, K. S. (2010). Self and identity across the life span. The Handbook of Life-Span Development.

McMahon, S. D., Wernsman, J., \& Parnes, A. L. (2006). Understanding prosocial behavior: The impact of empathy and gender among African American adolescents. Journal of Adolescent Health, 39(1), 135-137.

Mischel, W., Shoda, Y., \& Peake, P. K. (1988). The nature of adolescent competencies predicted by preschool delay of gratification. Journal of personality and social psychology, 54(4), 687.

Mustapha, S. M., Abd Rahman, N. S. N., \& Yunus, M. Md. (2010). Perceptions towards Classroom Participation: A Case Study of Malaysian Undergraduate Students. Procedia Social and Behavioral Sciences, 7(C), 113-121. 
INTERNATIONAL JOURNAL OF ACADEMIC RESEARCH IN PSYCHOLOGY

Vol. 6, No. 1, 2019, E-ISSN: 2312-1882 @ 2019 KWP

North, A. C., Tarrant, M., \& Hargreaves, D. J. (2004). The Effects of Music on Helping BehaviorA Field Study. Environment and Behavior, 36(2), 266-275. DOI: 10.1177/0013916503256263

Ogunboyed, M. O., \& Agokei, R. C. (2016). Prosocial Behavior of In-School Adolescents: The Perceived Influence of Self-Esteem, Peer Influence and Parental Involvement, British Journal of Education, Society \& Behavioural Science, 13(2), 1-9.

Penner, L. A., \& Finkelstein, M. A. (1998). Dispositional and structural determinants of volunteerism. Journal of Personality and Social Psychology, 74, 525-537.

Penner, L., Dovidio, J. F., Piliavin, J. A., \& Schroeder, D. (2005). Prosocial behavior: Multilevel Perspectives. Annual Review of Psychology, 56(1), 365-92.

DOI: 10.1146/annurev.psych.56.091103.070141

Piliavin, J. A., Dovidio, J. F., Gaertner, S. L., \& Clarke, R. D. (1981). Emergency Intervention. New York, NY: Academic Press.

Reynolds, W. M., Miller, G. E., \& Weiner, I. B. (2003). Handbook of psychology.

Salisch, M. V. (2001). Children's emotional development: Challenges in their relationships to parents, peers, and friends. International Journal of Behavioral Development, 25(4), 310-319.

Spasenovic, V. (2004). Prosocial behavior and academic achievement. Institute for Educational Research, 36, 131-150.

Wentzel, K. R., Barry, C. M., \& Caldwell, K. A. (2004). Friendships in Middle School: Influences on Motivation and School Adjustment. Journal of Educational Psychology, 96(2), 195203.http://dx.doi.org/10.1037/0022-0663.96.2.195

Kabir, A. H., \& Akter, F. (2014). Parental involvement in the secondary schools in Bangladesh: Challenges and a way forward. International Journal of Whole Schooling, 10(1), 1-18

Khalid, N., Islam, D. M. Z., \& Ahmed, M. R. M. (2019). Sentrepreneurial Training and Organizational Performance: Implications for Future. Humanities \& Social Sciences Reviews, 7(2), 590-593.

Alzgool, M. (2019). Nexus between green HRM and green management towards fostering green values. Management Science Letters, 9(12), 2073-2082.

Umrani, W., Ahmed, U., \& Memon, P. (2015). Examining the absorptive capacity construct: A validation study in the Pakistani banking context. Management Science Letters, 5(12), 10531058. 